\title{
Interpretation for the Countermeasures of Financial Management Based on the Sustainable Development of the Enterprise
}

\author{
Zhao Li ${ }^{1}$ \\ ${ }^{1}$ Xizang Minzu University, Xianyang, Shaanxi,712082
}

Keywords: Enterprise; sustainable development; financial management

\begin{abstract}
With the continuous development of social economy, people pay more and more attention to the internal financial management of enterprise. Thus, not only related enterprises are required to strengthen basic financial operation, but also financial personnel are called for taking into consideration an enterprise's long-term development goals in the process of financial management. This paper explains briefly related theories on the sustainable development of an enterprise and interprets the model of financial strategy for an enterprise's development, so as to promote the enterprise in completing the strategic objectives of sustainable development better at the same time of initiating the enterprise in the pursuit of corresponding economic growth.
\end{abstract}

\section{Introduction}

As China's economy is in the process of rapid development, an enterprise should not only improve the professional quality of managers and general employees, but also establish the right strategic objectives for the enterprise. Above all, the enterprise's financial management is the most basic guarantee for material resources. As financial personnel, they should perform effective sorting and collection for the data of overall finance, and measure the value of the enterprise itself in practice. Moreover, the development goals established for the enterprise shall be well checked and reasonable expectation shall be made. In the process of enterprise development, although the pursuit of economic interests is important, the long-term goal of an enterprise should be effective sustainable development of enterprises. Thus, it is required that an enterprise should perform the transformation of strategic level on financial management, so as to realize effective boost for the increased value (value increase) of the whole enterprise.

\section{Related Theories on Sustainable Development of An Enterprise}

As for the sustainable growth of an enterprise, the overall economic benefit is higher than fundamental project input in the aspect of value creation and the basic enterprise value can only be realized when the most optimal benefit is formed. In the process of development, basic capital cost includes not only the cost of fund, but also the effective cost of debt capital and equity capital. If the basic input of an enterprise is greater than the overall coast for operating of the enterprise, the overall economic development still shows the tendency of value loss although value of basic profit is positive. This suggests that the enterprise's effective cash didn't get due reward, forming a certain amount of money gap [1].So, only give full play to corresponding mechanisms, can the enterprise obtain virtuous economic benefits, which can promote the enterprise to establish optimized market competitiveness accordingly. 
In the operation process of an enterprise's value creation theory, we have clear requirements for the basic construction and implementation, and we'd establish basic forward looking, plyability and reality, so as to ensure that the overall value creation of the enterprise can effectively provide support to financial generation and distribution of the enterprise. Only when the enterprise's ability of sustainable development is stronger, the basic development space for the enterprise is greater and it is more able to coordinate and balance the influence of related factors.

As for the management of an enterprise, the basic sustainable development is built on the basis of an enterprise's virtuous growth. An enterprise shall make optical arrangements and analysis for the management level and financial resources of itself and make detailed study on important promoting policies. After taking into account comprehensively the related factors of all aspects, the strategic direction established can achieve sustained development. To get the substantial sustainable growth, we'd ensure that the overall goal is in line with the development need of the market when establishing the basic goal and we'd achieve and better the balance of basic rate of capital turnover according to the basic pattern of capital construction [2].

Whether an enterprise can realize real sustainable development depends on the basic strategic direction and substantial strategic ability of an enterprise. In order to guarantee the optimal development of financial strategy, an enterprise shall conduct comprehensive consideration for its own management ability. As for the development of an enterprise, raising of project fund not only includes the basic operating funds, but also depends on the basic requirements of an enterprise's development and business running, so as to ensure that the delivery and employment of capital funds can combine well with the materialized development of an enterprise. In addition, in the process of financial activities, an enterprise's concept on financial strategy shall be improved cognitively so as to ensure that the basic rules of finance can be effectively applied to strategic development and the effective balance between cost of funds and expenditure.

The progress of social economy has certain significance for the development of an enterprise and self optimal management of an enterprise can be realized through the goal of financial strategy for the society. In the process of value creation, an enterprise shall realize the basic value creation and the choice of business activities so as to ensure that the basic financial decisions can effectively promote the enterprise's basic competitiveness in market. Strategic target management of an enterprise is to ensure that an enterprise can realize the model design of value creation, and establish basic solutions and strategic combination under the guidance of the corresponding targets. In addition, in the process of development, an enterprise shall conduct strategic basic design for the basic financial development and management, and fully display the advantage of the projects within the enterprise. At the same time of obtaining rich economic benefit, the overall strategic targets shall be realized. [3].In the actual operation process of the enterprise, there are many factors that can affect the value creation, which requires serious comparison and check performed by relevant personnel on financial management. Although the basic financial investment has certain uncertainty, excellent strategic decision-making can be established, implemented and practiced as long as the financial management personnel focus on learning and accumulating related experience.

In the process of materialized management, relevant personnel on financial management shall secure the optimal establishment of enterprise value and realize the concentrated circulation of capital flow .by optimized strategic upgrading. In addition, in the process of investment, senior personnel on enterprise management can only control the general direction of the project while personnel on financial management in the enterprise shall conduct effective check for risk and value of the project, so as to ensure that it can conform to the basic decisions made by the administrative staff in the process of implementation. At the same time of promoting their own ability in project 
optimization, we'd collect effective information for the competitors, so as to ensure the fittest project analysis and project gambling at the same time of knowing your enemy well. [4].

In the process of enterprise running, personnel on financial management in the enterprise shall promote the establishment and implementation of the overall financial strategic objectives. The enterprise shall grasp the overall macroeconomic statistics, and make date collection and information arrangements against the background of the industry. After fully understanding the whole economic model, they'd determine the enterprise's basic value index, timely know amount of sales and basic economic growth rate of an enterprise and make actual prognosis for the sustainable growth ability of the enterprise according to the ROIC of the enterprise's materialization. In addition, personnel on internal financial management in the enterprise should also fully consider the internal conditions and special problems of the enterprise and establish the financing projects in view of the basic conditions. Moreover, the distribution of strategic targets shall be conducted for certain financing and distribution. And in the actual process of financial management, personnel on financial management shall conduct optimization of basic capital structure for development of the enterprise and they should improve their ladder of management, so as to guarantee the amount control of financing cost. In addition, in the execution of a corresponding management work, personnel on financial management in the enterprise shall not only achieve short-term and long-term return on investment, but also guarantee fully the abundant utilization of overall resources on development. Moreover, they shall make analysis and study for the basic condition of the enterprise, so as to realize the maintenance of self-competence, and eventually achieve the improvement of the enterprise's sustainable strategic objectives.

\section{Analysis on the countermeasures of financial management for the long-term development of an enterprise}

In the development process of enterprise running, the related personnel on financial management of the enterprise shall formulate corresponding planning on financial strategy, so as to ensure the healthy development of an enterprise's financial situation. In the process of establishing strategic goals, relevant financial personnel shall raise their own consciousness of planning, and check the basic information and the situation of the macro economy and the enterprise's internal financial environment. Moreover, feasible analysis report shall be provided to the senior management personnel of the enterprise. Such personnel must be aware that the corresponding internal and external environment will affect the development of the enterprise's materialization and the personnel shall analyze the basic connotation and nature of influential factors, so as to weak the degree of the negative influence. To this end, we'd not only set up corresponding strategic target, but also ensure that the operation of sustainable target can effectively promote the optimized development of the enterprise. In the corresponding planning and design process, the financial personnel shall not only establish planning on financial strategy, but also have profound cognition and implementation for long-term financial planning and outline of related activities, so as to ensure fundamentally the reasonable utilization of overall resources and promote the sustainable development of the enterprise.

In the process of financial project implementation, an enterprise shall conduct optimal management for the implementation of basic financial strategy and conduct systematical integration from the basic organizational structure and operation mechanism of the enterprise. In the process of promoting running of the whole project smoothly, the integration shall be realized between internal enterprise and external economy. In addition, in order to realize the basic evaluation system, the implementation situation of strategic objectives for overall financial management shall be checked 
and accepted so as to ensure that senior personnel of the enterprise can timely propose effective advices on feedback. In the whole process of financial strategic management, the basic goal lies in the organic circulation of the whole value and the control of internal financing within the enterprise. Moreover, we'd make comprehensive management for the substantiated financing and assigned project and we'd meet with the basic requirements of capital increase at the same time of employing corresponding funds. The key point of financial strategy implementation is coordinating the relationship between the economic norms and value creation so as to ensure the organic balanced entirety of the two. At present when the market economy is developing rapidly, relevant personnel on financial management shall integrate the effect of basic earnings, cash flow and value creation, so as to guarantee that realization of the financial strategy objectives is based on the effective establishment of value. In short, if an enterprise aims to get sustainable development and realize the goal of financial strategy, it shall improve the basic consciousness of personnel on financial management and ensure the optimization of resources and projects.

As for an enterprise's control of financial strategy, only the effective feedback on information can guide the project. Moreover, personnel on financial management shall make comparison between the basic implementation effect and the objects of financial management, thus forming effective result output through essential data and information. Moreover, effective correction shall be done for the disadvantageous deviation occurred in the process of project implementation and the overall strategic development shall be close to the basic scheduled aim. In the process of an enterprise's development, related goal on strategic development shall aim at the whole enterprise and make optimal modification according to the whole financial objectives of an enterprise, forming a good relationship of auxiliary. In the operation process of financial management in the enterprise, we should not only guarantee the stability of the fundamental and sustainable development planning, but also ensure that the strategic objective can conform to the versatile situation of the market. [6].

The most outstanding characteristic of market economy is the unpredictable changes of the market and corresponding goal for strategic management estimate only the general condition. If the deviation of goal and reality occurs in the actual running of an enterprise, related personnel on financial management shall modify the strategic scheme of the whole project and make timely rectifying and treatment. In the actual process of an enterprise's operation, influence factors are both

subjective and objective, which requires the relevant personnel to start from the overall situation of an enterprise and form the systematical and integrated structure on imagination.

Conclusion:

In a word, in the process of an enterprise's development, senior personnel on management and personnel on financial management shall treat the sustainable development as the basic strategic orientation, so as to realize the enterprise's maximum value and make effective estimation for the degree of an enterprise's basic risk degree. Personnel on financial management in an enterprise shall conduct optimal control for the basic strategic model and establish a periodic value creation plan, so as to ensure that the enterprise can gain a foothold in the increasingly fierce market competition. Personnel on enterprise management shall make reasonable estimation for the condition of basic development and establish the substantial strategic target, so as to further promote the enterprise in obtaining the sustainable development of a project.

\section{Acknowledgements}

Subject: the project of humanities and social science for university of high learning in Tibet 2015, No. sk2015-65 


\section{References:}

[1] Qin Weiping. On the Sustainable Growth of Financial Management Strategy in Enterprise [J]. Market modernization, 2013, 17 (20) : 174-175.

[2] Zhang Xiaowei. Study on the Sustainable Growth of Financial Management Strategy in Enterprise [J]. Accounting of China's Township Enterprises, 2015, 32 (6) : 105-105106.

[3] Zhao Wei. Research on the Sustainable Growth of Financial Management Strategy in Enterprise [J]. Money China, 2014, 12 (29) : 225-225.

[4] Zhang Xiaoyan. Sustainable Growth of Financial Management Strategy in Enterprise [J]. Modern Business, 2013, 44 (8) : 215-216

[5] Li Xin. On the Sustainable Growth of Financial Management Strategy in Enterprise [J]. New Finance and Economics (theory), 2013, 32 (10) : 124-124.

[6] He Yingping. Introduction to the Sustainable Growth of Financial Management Strategy in Enterprise [J]. Operaters, 2014, 29 (12) : 58-58. 